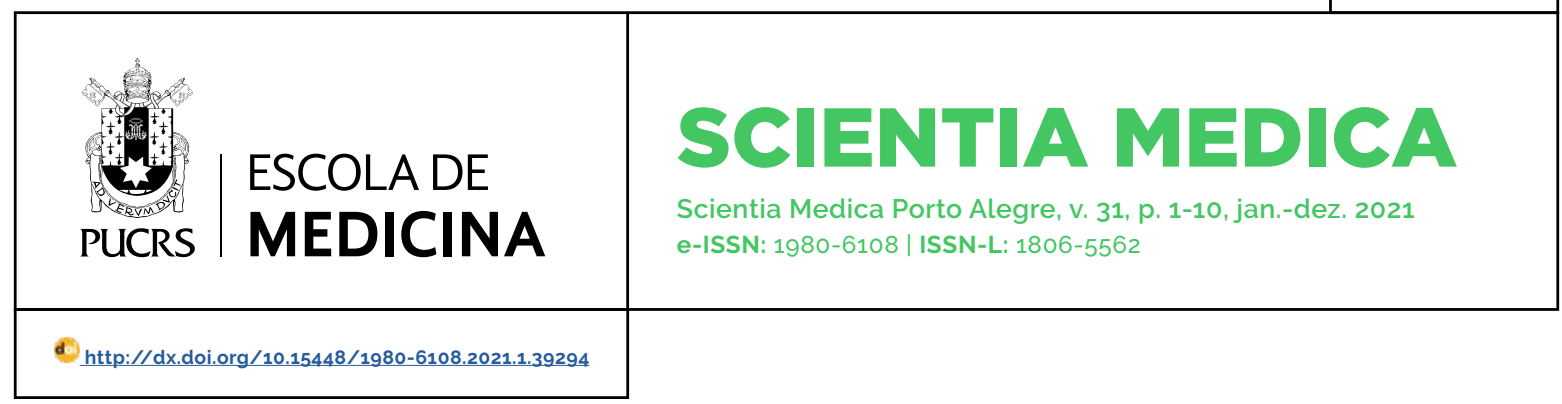

EDUCATION IN HEALTH SCIENCES

\title{
The challenge of understanding, evaluating and providing feedback on regulation during group learning
}

\author{
O desafio em entender, avaliar e fornecer feedback em regulação durante \\ aprendizagem em grupo
}

\author{
John Sandars ${ }^{1}$ \\ orcid.org/0000-0003-3930-387X \\ john.sandars@edgehill.ac.uk

\section{Dario Cecilio- \\ Fernandes ${ }^{2}$ \\ orcid.org/0000-0002-8746-1680 \\ dario.fernandes@gmail.com}

\section{Roghayeh Gandomkar ${ }^{3}$ orcid.org/0000-0002-7262-6243 gandomkarr@gmail.com}

\section{Rakesh Patel ${ }^{4}$}

orcid.org/0000-0002-5770-328X rakesh.patel@nottingham.ac.uk

Received on: Oct.02 $2^{\text {sd }}, 2020$ Approved on: Feb. 15 th, 2021
Abstract: Learning in groups is commonly used in academic and clinical health professions education (HPE). There is growing recognition that regulation during learning is essential for both the individual learner and group learning. The authors in this article propose a practical approach for understanding, evaluating and providing feedback on regulation during group learning. The approach is informed by previous studies conducted in other areas of education. Three varieties of regulation during group learning are discussed: individual, co-regulation and shared regulation. Each variety of regulation has a focus on three essential activities during group learning: task, social and motivation. Illustrative scenarios are presented to describe how the approach can be practically used in HPE. The specific and additional focus on regulation can enhance current approaches for providing feedback on group learning and the authors discuss recommendations for practical implementation and future research.

Keywords: Group learning; Feedback; Regulation during learning; Social regulation

Resumo: Aprendizagem em grupo é muito utilizada no ensino dos profissionais de saúde tanto na parte acadêmica quanto na parte clínica. Há um crescente reconhecimento de que a regulação durante aprendizagem é essencial para o individuo e em grupo. Os autores deste artigo propõem um modelo prático para entender, avaliar e fornecer feedback em regulação durante a aprendizagem em grupo. Esse modelo é baseado por estudos publicados em outras áreas de educação, sendo composto por três variações de regulação durante aprendizagem em grupo, a saber, individual, corregulação e regulação compartilhada. Cada variação de regulação foca em três atividades essenciais durante a aprendizagem em grupo: tarefa, social e motivacional. Cenários ilustrativos são apresentados para descrever como esse modelo pode ser utilizado em ensino em saúde. O foco especifico e adicional em regulação pode melhorar práticas de feedback em aprendizagem em grupos e os autores discutem recomendações para implementações práticas assim como pesquisas futuras

Palavras-chaves: Aprendizagem em grupo; Feedback; Regulação durante a aprendizagem; Regulação Social

\section{Introduction}

Learning in groups, which we will refer to as group learning throughout the article, has been commonly used across the continuum of health professions education (HPE) and in a variety of different academic and clinical situations. Examples include problem based learning (1) and team 
based learning in academic situations (2) and also simulation training (3) and inter-professional team training in clinical situations (4). In all of these situations, group learning is both a process and an outcome (5) The essential characteristic is the interaction of two or more individuals, with the acquisition of new knowledge, skills, experiences, and perspectives from others in the group (5). Research on the outcome of group learning shows increased new knowledge and understanding compared with learning alone $(5,6)$. In addition, there is development of important social skills that are essential for future group learning and working together, including problem solving and positive interdependence with acceptance of diversity and negotiation of differences in opinion (6 - 8). There is the potential that the new knowledge and social skills that have been acquired during group learning can also be applied to future healthcare, especially when there is an increasing emphasis on learning and working together in inter-professional groups $(9,10)$.

A challenge for all HPE educators interested in improving the effectiveness of group learning is to understand and evaluate the process that occurs during learning so that it can inform developmental feedback to increase the effectiveness of group learning (5). There has been increasing interest in HPE about understanding regulation during both academic and clinical learning situations (11), with a focus on how learners are actively engaged in managing their learning by using an adaptive process to optimize their learning (12). This interest in regulation during learning in HPE has almost exclusively been on the individual learner but recently there has been increasing recognition of the importance of regulation during group learning in both academic and clinical situations $(13,14)$.

The purpose of this article is to propose a practical approach for educators to understand and evaluate regulation during group learning in HPE, with the intention that this approach can guide developmental feedback for improving group learning. Providing feedback on regulation is essential for developing the skills for how learners can optimize their future learning (15 - 17). We are not aware of a similar approach for understanding, evaluating, and providing feedback on regulation during group learning in HPE. Our approach is informed by previous studies from other areas of education and several illustrative examples are presented to demonstrate how this approach can be practically applied to a variety of academic and clinical group learning situations. Understanding, evaluating, and providing feedback on regulation during group learning by educators requires a shift in focus from an individual learner to regulation of learning between several individuals. It is also interesting to note that current feedback that learners receive about their group learning is often perceived as not useful to guide their future learning (18).

\section{Understanding regulation during learning}

There are several models that describe regulation during learning by individuals, which is often called self-regulation (12). Optimizing learning during different learning situations, such as exploring the causes of heart failure or how to insert a venous cannula, requires an active and cyclical metacognitive adaptive process of the essential cognitive and motivational aspects of learning, which also includes the important emotional factors that can influence motivation $(19,20)$.

A feature of all models of regulation during learning is the description of several phases but there are slight differences in the nomenclature and number of phases. A three-phase model of planning, monitoring and adaptive change is presented and is based on a commonly used model (19).

\section{Before learning}

The individual initially evaluates the demands of the learning situation, including the expected cognitive and motivational demands, and develops a plan to achieve learning. This plan includes setting a goal, which is the expected outcome of the learning, and the selection of an appropriate strategy and specific techniques to attain the goal. The focus of the planning may be on cognitive task- related activities, such 
as selecting a problem-solving model for an academic task or a specific procedural technique for a clinical skill. The focus of the plan may also be on motivational-related activities, such as controlling anxiety or enhancing self-efficacy beliefs by recalling previous successful, or unsuccessful, learning.

\section{During learning}

The individual monitors the extent to which their chosen cognitive and motivational strategy and techniques are being optimised to attain the intended goal. In response to monitoring, the individual can make adaptive changes to their chosen cognitive and motivational goals, strategies, and techniques in an attempt to optimally attain the intended goal.

\section{After learning}

This is the opportunity for the individual to reflect on how they have approached the learning situation and to consider the need to modify their future planning before learning. Feedback from another individual, such as learner or an educator, can have important additional benefits, including evaluation and feedback from a different perspective (15).

Research has highlighted the importance of each phase informing the next as an integrated cyclical process, with monitoring and making adaptive changes during learning being considered as essential to ensure that the cognitive and motivational aspects of learning can be optimal for the situation (20).

\section{Understanding regulation during group learning}

Several studies from other areas of education have provided greater understanding of regulation during group learning, especially in computer supported collaborative groups and learning groups in young children $(21,22)$. This research has consistently identified three core varieties of regulation during group learning: (a) Individual regulation: An individual only
regulates their own learning (22).

(b) Co-regulation: An individual provides and/or receives regulation by social interaction between one or more other learners (23).

(c) Shared regulation: The regulation of learning occurs between all learners and is collectively shared between these learners (24).

Within each variety of regulation, three core learning activities have been identified and each activity must be regulated by planning, monitoring and adaptive change to optimise learning (25):

(a) Task-related activities: These activities have a focus on the knowledge that is required to learn in the situation, including clarification of the goal and choosing a strategy or technique, such as using a mnemonic to structure new information or an airway management approach in a simulated unconscious patient.

(b) Social-related activities: These activities have a focus on the social interactions between the learners that are required to learn in the situation, such as the allocation of roles and responsibilities.

(c) Motivation-related activities: These activities have a focus on the essential motivational support that is required to learn in the situation, such enhancing self- efficacy beliefs or reducing anxiety.

Our practical approach for understanding regulation during group learning in HPE is also based on three core varieties of regulation and the three core learning activities that have been identified in other areas of education. This is summarised in Table 1. 
TABLE 1 - The varieties and learning activities of regulation during group learning

\begin{tabular}{llll}
\hline $\begin{array}{l}\text { Learning } \\
\text { activities }\end{array}$ & \multicolumn{1}{c}{$\begin{array}{c}\text { Individual (self) } \\
\text { regulation }\end{array}$} & \multicolumn{1}{c}{ Co-regulation } & Shared regulation \\
\hline $\begin{array}{l}\text { Cognitive- } \\
\text { related }\end{array}$ & $\begin{array}{l}\text { Knowledge and skills } \\
\text { applied by only one learner } \\
\text { to optimise learning. }\end{array}$ & $\begin{array}{l}\text { Knowledge and skills provided } \\
\text { and /or received between one or } \\
\text { more learners to optimise learning. }\end{array}$ & $\begin{array}{l}\text { Knowledge and skills } \\
\text { shared between all learners } \\
\text { to optimise learning. }\end{array}$ \\
Social-related & $\begin{array}{l}\text { No social interactions by the } \\
\text { individual learner required } \\
\text { to optimise learning. }\end{array}$ & $\begin{array}{l}\text { Social interactions provided and / } \\
\text { or received between one or more } \\
\text { learners to optimise learning }\end{array}$ & $\begin{array}{l}\text { Social interactions shared } \\
\text { between all learners to } \\
\text { optimise learning. }\end{array}$ \\
Motivation- & $\begin{array}{l}\text { Motivation applied by only } \\
\text { one learner to optimise } \\
\text { learning. }\end{array}$ & $\begin{array}{l}\text { Motivation provided and /or } \\
\text { received between one or more } \\
\text { learners to optimise learning. }\end{array}$ & $\begin{array}{l}\text { Motivation shared between } \\
\text { all learners to optimise } \\
\text { learning. }\end{array}$ \\
\hline
\end{tabular}

Regulation during group learning is complex since individual regulation, co-regulation and shared regulation are occurring simultaneously (26). Each individual learner has to continually regulate their own learning to optimize learning but sometimes an individual requires additional regulation support from other learners in the group (26). This support occurs as short and transitory episodes in which co-regulation occurs between only one or two learners, either when a learner requests additional support or when a learner recognises that another learner requires additional support (26). Research suggests that shared regulation between all learners is associated with maximum learning for each learner in the group $(21,26)$. However, shared regulation may require additional support, especially at the beginning of a learning situation and also at critical moments during the situation when the group is faced with evolving increased demands. At these times, transitory episodes of co-regulation can act as a 'kick-start' to initiate shared regulation (26).

\section{Evaluation of regulation during group learning}

Our understanding of regulation provides the basis for our practical approach for evaluating regulation during group learning in HPE. A structured method is required to identify the three varieties of regulation (individual, co-regulation and shared regulation) but a deeper understanding of regulation during group learning requires further identification of how the three core learning activities within each variety are being regulated.

We recommend two practical methods for evaluating regulation to inform developmental feedback that are based on previous research in other areas of education: structured interviews and observations (27). Each method provides a different lens for evaluating regulation during group learning. For each method, we provide illustrative scenarios to demonstrate a practical approach to evaluating regulation during group learning and how this can inform feedback.

\section{(a) Structured interviews}

A structured interview provides a useful method for identifying an individual's perspective of both their own regulation but also their contribution to regulation of the whole group. However, like all selfreport tools, interviews can be prone to inaccurate responses related to recall and social desirability biases (28). Questions can explore an individual's self- regulation and their intention to begin coregulation to optimize their own learning, but also about the reasons for not putting their intention to provide or receive co-regulation into action. An illustrative example is provided in Scenario 1.

\section{Scenario 1:}

Greg, a first year student, complained to his group facilitator that he was "not learning anything" in his problem-based learning group. His facilitator asked several questions to identify individual regulation used by Greg in a recent 
group where the learning task presented to the group was a patient with a weak leg and the CT scan showing a brain tumour.

Facilitator: What was the main challenge for you?

Greg: I felt really anxious since I had no idea about why the leg was weak.

Facilitator: How did you deal with your anxiety?

Greg: I just said nothing and became more anxious since I was not contributing to the group.

Facilitator: Who could have helped you to deal with your anxiety?

Greg: I could have mentioned to Judith that I was anxious about not knowing the answers - she is always so reassuring to me and could have given me support.

The scenario highlighted that the main problem for Greg was his individual regulation of motivation-related activities. It is interesting that he was monitoring his learning and recognised the need to obtain additional regulatory support from another student but had not adapted by obtaining support on this occasion. The facilitator subsequently provided feedback by probing why Greg had not adapted and obtained motivationrelated support from Judith and there was a subsequent discussion of the importance of planning to seek co-regulation when feeling anxious during group learning.

Questions can also explore the perspectives of all individuals in a group about the extent of shared regulation, but also about the reasons for not putting shared regulation into action. An illustrative example is provided in Scenario 2.

\section{Scenario 2:}

The group is expected to work as a team to implement an advanced life support protocol whilst managing a simulated cardiac arrest situation. The facilitator noticed that the group had initially nominated a team leader but then the group appeared to struggle with the twominute rotation of rescuers in order to ensure chest compressions were effective (delivered at the correct depth and rate) when performing cardio-pulmonary resuscitation.
The facilitator directed questions to all members of the group: Was there a time whilst working together that you considered that you were struggling?

Hamid: We did not have any direction with the swapping over of the rescuers at one point, particularly when the team leader was distracted. We could have taken control of the situation at that point, just to keep everything going whilst the leader was otherwise occupied.

Jafar: This is difficult because we had not worked together before

Arash: We could have sorted it out between ourselves so that the timing and coordination of the resuscitation would continue.

Sina: Yes ... I agree. We were struggling but found it difficult to sort it out.

The questioning by the facilitator highlighted that Hamid, Jafar, Arash and Sina appeared to be aware that the group was struggling, and this suggests that they were monitoring sharedregulation of social-related activities at the time of the situation. However, their approach to making adaptive changes to increase shared -regulation of social-related activities for supporting the group could have been improved. If this action has been taken, it would have also subsequently improved the shared-regulation of task-related activities related to the rotation of rescuers. The feedback by the facilitator led to a discussion about all individuals in the group taking responsibility for monitoring and making adaptive changes to social-related activities when performing resuscitation to ensure optimal social interaction. The facilitator also discussed the importance of goal setting and planning the shared -regulation of social -related activities at the beginning of the situation to ensure that all the members of the group were more acquainted with each other, using strategies such as each individual quickly introducing themselves.

\section{(b) Observations}

Observation of regulation during group learning provides a useful lens but can be 
complicated. Analysis of communication between individuals, including both speech and non-verbal communication, provides a highly detailed and structured moment-by-moment method to understand regulation during group learning (29). The use of observation tools can provide useful information about the extent and moments of co-regulation between individuals and shared regulation during group learning. However, similar to all observation tools, there can be cognitive overload for the external person performing the observation but also for when this feedback is provided and for the person receiving the feedback (30).

An illustrative example is provided in Scenario 3.

\section{Scenario 3 :}

The facilitator of a problem-based learning group is aware that the group of first year students had a moment when they were struggling during the discussion of a case of a patient with jaundice. However, the students had overcome these difficulties. The facilitator had video-recorded the session and reviewed the recording to identify how the students had overcome their difficulties by regulation during group learning. Two sequences were chosen for feedback and discussion by the facilitator:

\section{Sequence 1}

Maria: llooking at Duartel - What's your opinion?

Duarte: Is there an obstruction in the bile ducts?

Clara: Um .... Maybe lab tests could help us to see if there is an obstruction?

Beatriz: Yes .... Blood tests are useful

In this sequence, Maria was monitoring the social-related and task-related activities of the learners in the group and noted the need to coregulate Duarte, who had been silent and not contributing to the group. Duarte subsequently contributed to the discussion in the group. The contribution from Duarte also appeared to 'kickstart' the group, which continued into Sequence 2 .

Sequence 2

Rafael: We could check bilirubin levels?
Beatriz: Yeah ...... conjugated and unconjugated?

Maria: What's the difference?

Camila: I am not sure

Duarte: We can work out the answer - we have worked in the past to find answers to problems

Clara: Yes, we have worked well before to solve problems

Afonso: The liver conjugates bilirubin

Lucas: So .... if there is a high level of unconjugated bilirubin, the problem is before the liver ...... and if there is a high level of conjugated bilirubin, the problem is after the liver.

In this sequence, there is shared regulation by monitoring and making adaptive changes of the taskrelated activities between students Rafael, Beatriz, Maria, Camila, Alfonso and Lucas. Duarte and Clara were monitoring shared regulation of motivationrelated activities and made adaptive changes.

The facilitator provided feedback by initially leading a discussion on Sequence 1 to highlight the importance of co-regulation of both socialrelated and task-related activities, for both the individual but also to 'kick start' group learning. A subsequent discussion by the facilitator of Sequence 2 highlighted the importance of shared regulation of both task-related and motivationrelated activities for effective group learning.

\section{Feedback on regulation during group learning}

Feedback after learning promotes reflection to stimulate future change in learning behaviour but it is essential that it is relevant to the learner, with a specific focus on the evaluation of appropriate, and not so appropriate, behaviours (31). However, there are increasing concerns about providing feedback on group learning in academic and clinical simulation situations since this feedback is often not fully aligned to the essential aspects of group learning $(32,33)$. For example, one widely used simulation model has a focus on leadership, problem solving, situational awareness, resource utilization and communication whilst performing 
the learning task but this does not include the essential regulation aspects (34).

The objective evaluation of regulation during group learning in HPE, with the intention to inform feedback, can be provided by using both interviews and observations for identifying the three varieties of regulation (individual, co-regulation and shared) and the regulation of the three core learning activities. The choice of method to identify regulation will be determined by the intended focus but also the availability of resources, especially the availability of video-recording.

We recognise that an important limitation of all evaluation methods, and especially observations, is cognitive overload by the provider of feedback since there are often too many items to evaluate by the educator and this limits the potential for providing detailed feedback. One approach for overcoming this overload is to narrow the focus of evaluation, such as only on critical moments of regulation during group learning. The use of videorecording of group learning can be very useful to identify specific time-limited segments of critical moments, such as when the group appears to be struggling in the situation. These moments can be selected by either the learners or by the observer for evaluation and feedback. For example, the focus could be on who initiates co-regulation and whether this 'kick starts' shared regulation. This finding would be important for feedback to the group so that learners can recognise these times and respond with shared regulation, which is essential for effective group learning (26).

The intention of the practical approach described in this article is on regulation but for feedback to be most effective it is likely to also require the inclusion of strategies and specific techniques within the three core learning activities (16). For example, feedback on specific strategies and techniques in task-related activities include using checklists; social -related activities, such as clear verbal and non-verbal communication of ideas; and motivation-related activities, such as enhancing self-efficacy by positive self-talk. This approach to providing 'regulation enhanced' feedback, which includes both regulation and strategies and techniques, has been described for providing feedback on self-regulation of individual learning (35), but it uncertain whether this can also be applied to group learning. Similar to the provision of feedback for other learning, it is also important that the educator creates a supportive environment and to actively involve the participants in identifying aspects that require further development (36).

Future directions on understanding, evaluating and feedback on regulation during group learning

Our proposed practical approach is the first in HPE for understanding and evaluating regulation during group learning, with an intention to provide feedback on the essential regulation during group learning.

An essential direction for further research and development is on how the approach can be implemented in practice. An initial priority is to develop and assess the evaluation methods. Templates for structured interviews and videoobservation will need to be valid and reliable, especially for identifying the complexity of the changing sequences of co-regulation and shared regulation during group learning (37). This research will require inter-rater reliability studies and the iterative development of the evaluation methods in partnership with the intended users to ensure that the methods are 'fit for purpose'. The next priority is conducting feasibility and development research to ensure that educators can easily integrate the new approach into their usual debriefing and feedback practice but also that learners perceive that the feedback on regulation during group learning is useful to inform their future learning. We also recommend that this research is in partnership with the intended users. Finally, effectiveness studies of the impact of feedback on subsequent group learning can be conducted when appropriate evaluation methods and a practical approach for evaluation and feedback has been developed. An exciting area for future research is also whether feedback on regulation during group learning can have an impact on group learning situations and working together in healthcare.

We have also identified an important area for future research that has a focus on understanding 
the importance of times during group learning when co-regulation is most appropriate and also the factors that enable and constrain its use. Research could explore who takes responsibility to co-regulate other individuals in the group and also the factors that influence if co-regulation initiates a shift to shared regulation of learning. This has implications for providing feedback at times of critical importance when in similar learning situations.

\section{Conclusion}

Developing group learning in HPE requires increased attention on providing effective feedback that has a specific focus on developing the essential regulation during group learning. Our proposed practical approach provides an opportunity to increase understanding of regulation during group learning so that this understanding can inform evaluation and feedback after learning. We consider that specific feedback on regulation during group learning can enhance current approaches that are used for providing feedback on group learning in HPE.

\section{Notes}

Funding/Support: Dario Cecilio-Fernandes is partially funded by FAPESP - São Paulo Research Foundation [Young Investigator Grant number 2018/15642-1]. The views and opinions are entirely those of the author and the funder had no role in selection of content, decision to publish, or preparation of the manuscript.

\section{Conflicts of interest disclosure}

The authors declare no competing interests relevant to the content of this study.

\section{Authors' contributions.}

All authors made a substantial contribution to the conception of the article, drafting the article and final approval of the version to be published. All authors agree to be accountable for all aspects of the work in ensuring that questions related to the accuracy or integrity of any part of the work are appropriately investigated and resolved.
Availability of data and responsibility for the results

All the authors declare to have had full access to the available data and they assume full responsibility for the integrity of these results.

\section{REFERENCES}

1. Qin Y, Wang Y, Floden RE. The effect of problem-based learning on improvement of the medical educational environment: a systematic review and meta-analysis. Med Prin Pract. 2016;25(6):525-532. https://doi. org/10.1159/000449036

2. Reimschisel T, Herring AL, Huang J, Minor TJ. A systematic review of the published literature on team-based learning in health professions education. Med Teach. 2017:39(12):1227-1237. https://doi.or$\mathrm{g} / 10.1080 / 0142159 \times .2017 .1340636$

3. Patel EA, Aydın A, Desai A, Dasgupta P, Ahmed K. Current status of simulation-based training in pediatric surgery: a systematic review. J Pediatr Surg. 2019:54(9):18841893. https://doi.org/10.1016/j.jpedsurg.2018.11.019

4. Baik D, Abu-Rish Blakeney E, Willgerodt M, Woodard $N$, Vogel M, Zierler B. Examining interprofessional team interventions designed to improve nursing and team outcomes in practice: a descriptive and methodological review. J Interprof Care. 2018;32(6):719-727. https://doi. org/10.1080/13561820.2018.1505714.

5. Johnson DW, Johnson RT. Cooperation and competition: Theory and research. Edina, MN: Interaction Book Company; 1989.

6. Laal M, Ghodsi SM. Benefits of collaborative learning. Procedia Soc Behav Sci. 2012; 31:486-490. https://doi. org/10.1016/j.sbspro.2011.12.091.

7. Roseth CJ, Johnson DW, Johnson RT, Promoting early adolescents' achievement and peer relationships: The effects of cooperative, competitive, and individualistic goal structures. Psychol Bull. 2008;134(2):223-246. https://doi.org/10.1037/0033-2909.134.2.223.

8. Rosen MA, DiazGranados D, Dietz AS, et al; Teamwork in healthcare: Key discoveries enabling safer, high-quality care. Am Psychol. 2018;73(4):433-450. https://doi. org/10.1037/ampo000298.

9. Schmutz JB, Meier LL, Manser T. How effective is teamwork really? The relationship between teamwork and performance in healthcare teams: a systematic review and meta-analysis. BMJ Open. 2019;9(9): e028280. https://doi.org/10.1136/bmjopen-2018-028280.

10. Lutfiyya MN, Chang LF, McGrath C, Dana C, Lipsky MS. The state of the science of interprofessional collaborative practice: A scoping review of the patient health-related outcomes based literature published between 2010 and 2018. Plos One. 2019:14(6):e0218578. https://doi.org/10.1371/journal.pone.0218578. 
11. Siddaiah-Subramanya $M$, Nyandowe $M$, Zubair $O$. Self-regulated learning: why is it important compared to traditional learning in medical education? Adv Med Educ Pract. 2017:17(8):243-246. https://doi.org/10.2147/ AMEP.S131780.

12. Panadero E. A review of self-regulated learning: Six models and four directions for research. Front Psychol. 2017; 8:422. https://doi.org/10.3389/fpsyg.2017.00422.

13. Demirören M, Turan S, Öztuna D. Medical students' self-efficacy in problem-based learning and its relationship with self-regulated learning. Med Educ Online. 2016;21(1):30049. https://doi.org/10.3402/meo.v21.30049.

14. Duffy MC, Azevedo R, Sun NZ, Griscom SE, Stead $\mathrm{V}$, Crelinsten L, Wiseman J, Maniatis T, Lachapelle K. Team regulation in a simulated medical emergency: An in-depth analysis of cognitive, metacognitive, and affective processes. Instr Sci. 2015:43(3):401-426. https:// doi.org/10.1007/s11251-014-9333-6.

15. Butler DL, Winne PH. Feedback and self-regulated learning: A theoretical synthesis. Rev Educ Res.1995;65(3):245-281. https://doi. $\mathrm{org} / 10.3102 / 00346543065003245$

16. Hattie J, Timperley $\mathrm{H}$. The power of feedback. Rev Educ Res. 2007:77(1):81-112. https://doi. org/10.3102/003465430298487.

17. Patel R, Green W, Shahzad MW, Church H, Sandars J. Using a self-regulated learning-enhanced video feedback educational intervention to improve junior doctor prescribing. Med Teach. 2020;42(8):886-895. https://doi.org/10.1080/0142159X.2020.1748183.

18. Parikh A, McReelis K, Hodges B. Student feedback in problem based learning: a survey of 103 final year students across five Ontario medical schools. Med Educ. 2001;35(7):632-636. https://doi.org/10.1046/j. 1365-2923.2001.00994.x.

19. Zimmerman BJ. A social cognitive view of self-regulated academic learning. J Educ Psychol. 1989;81(3):329 -339. https://doi.org/10.1037/0022-0663.81.3.329.

20. Zeidner M, Stoeger H. Self-Regulated Learning (SRL): A guide for the perplexed. High Abil Stud. 2019;30(12):9-51. https://doi.org/10.1080/13598139.2019.1589369.

21. Järvelä S, Hadwin AF. New frontiers: Regulating learning in CSCL. Educ Psychol. 2013;48(1):25-39. https:// doi.org/10.1080/00461520.2012.748006.

22. Grau V, Whitebread D. Self and social regulation of learning during collaborative activities in the classroom: the interplay of individual and group cognition. Learn Instr. 2012; 22:1-12. https://doi.org/10.1016/j.learninstruc.2012.03.003.

23. Hayes S, Uzuner-Smith S, Shea P. Expanding learning presence to account for the direction of regulative intent: self-, co-and shared regulation in online learning. J Interact Online Learn. 2015; 19:1-19. https://doi. org/10.24059/olj.v19i3.666.
24 Hadwin A, Oshige M. Self-regulation, coregulation, and socially shared regulation: exploring perspectives of social in self-regulated learning theory. Teach Coll Rec. 2011; 113:240-264.

25. Saab N. Team regulation, regulation of social activities or co-regulation: Different labels for effective regulation of learning in CSCL. Metacogn Learn. 2012;7(1):1-6. https://doi.org/10.1007/s11409-011-9085-5.

26. Panadero E, Järvelä S. Socially shared regulation of learning: A review. Europ Psychol. 2015;20(3):190-203. https://doi.org/10.1027/1016-9040/a000226.

27. Zimmerman BJ. Investigating self-regulation and motivation: Historical background, methodological developments, and future prospects. Am Educ Res J. 2008;45(1):166-183. https://doi. org/10.3102/0002831207312909.

28. Van de Mortel TF. Faking it: social desirability response bias in self-report research. Aust J Adv Nurs. 2008;25(4):40-48.

29. Bull P. Communication under the microscope: The theory and practice of microanalysis. New York, NY: Routledge; 2013. https://doi.org/10.4324/9780203753828.

30. Bracco F, De Tonetti G, Masini M, Passarelli M, Geretto F, Celleno D. Crisis resource management in the delivery room: development of behavioral markers for team performance in emergency simulation. Int $J$ Environ Res Public Health. 2018;15(3):439. https://doi. org/10.3390/ijerph15030439.

31. Kelly E, Richards JB. Medical education: giving feedback to doctors in training. BMJ. 2019:366:L4523. https://doi.org/10.1136/bmj.l4523.

32. Meijer H, Hoekstra R, Brouwer J, Strijbos J. Unfolding collaborative learning assessment literacy: a reflection on current assessment methods in higher education. [published online ahead of print March 6, 2020]. Assess Eval High Educ. doi:10.1080/02602938.2020.1729696.

33. Endacott R, Gale T, O'Connor A, Dix S. Frameworks and quality measures used for debriefing in team-based simulation: a systematic review. BMJ Simul Technol Enhanc Learn. 2019:5:61-72. https://doi.org/10.1136/ bmjstel-2017-000297.

34. Kim J, Neilipovitz D, Cardinal P, Chiu M, Clinch J. A pilot study using high-fidelity simulation to formally evaluate performance in the resuscitation of critically ill patients: The University of Ottawa Critical Care Medicine, High-Fidelity Simulation, and Crisis Resource Management I Study. Crit Care Med. 2006:34(8):2167-2174. https://doi.org/10.1097/01.CCM.0000229877.45125.CC.

35. Leggett H, Sandars J, Roberts T. Twelve tips on how to provide self-regulated learning (SRL) enhanced feedback on clinical performance. Med Teach. 2019;41(2):147-151. https://doi.org/10.1080/0142159X.2017.1407868.

36. Telio S, Ajjawi R, Regehr G. The "educational alliance" as a framework for reconceptualizing feedback in medical education. Acad Med. 2015:90(5):609-614. https:// doi.org/10.1097/ACM.0000000000000560. 
37. Malmberg J, Järvelä S, Järvenoja H. Capturing temporal and sequential patterns of self-, $\mathrm{CO}^{-}$, and socially shared regulation in the context of collaborative learning. Contemp Educ Psychol. 2017; 49:160-74. https:// doi.org/10.1016/j.cedpsych.2017.01.009.

\section{John Sandars}

MD from University of Manchester, Manchester, UK; Professor of Medical Education, Edge Hill University Medical School, Ormskirk, UK.

\section{Dario Cecilio-Fernandes}

PhD from the University of Groningen, Groningen, Netherlands; researcher in the Department of Medical Psychology and Psychiatry, School of Medical Sciences, University of Campinas, Brazil.

\section{Roghayeh Gandomkar}

PhD from Tehran University of Medical Sciences, Tehran, Iran; Assistant Professor, Department of Medical Education, Tehran University of Medical Sciences, Tehran, Iran.

\section{Rakesh Patel}

MD from University of Leicester, Leicester, UK; Clinical Associate Professor of Medical Education, University of Nottingham, UK and honorary consultant nephrologist, Nottingham University Hospitals NHS Trust, UK.

\section{Mailing address:}

John Sandars

Edge Hill University

St Helens Road, L39 4QP.

Ormskirk, Lancashire, United Kingdom. 